\title{
Implementasi Algoritma TEA dan Pontifex Dalam Keamanan Data File Dokumen
}

\author{
Saripah Aini \\ Prodi Teknik Informatika, STMIK Budi Darma, Medan, Indonesia \\ Email: saripahaini13@gmail.com \\ Submitted 10-05-2020; Accepted 01-06-2020; Published 14-06-2020
}

\begin{abstract}
Abstrak
Keamanan data merupakan salah satu aspek terpenting dalam teknologi informasi. Dengan tingkat keamanan yang tinggi, diharapkan informasi yang disajikan dapat terjaga keasliannya. Pada tugas akhir ini dibentuk suatu system yang mengamankan data dan informasi yang tersimpan pada computer dari gangguan para kriptanalis. Tahapan yang penulis lakukan untuk melakukan proses pembentukan system tersebut meliputi tahapan analisa permasalahan,algoritma dan flowchart beserta pemodelan struktur program dan desain antar muka aplikasi, sehingga aplikasi yang terbentuk menjadi mudah dipergunakan dan memiliki fungsi yang optimal. Dengan menggunakan Algoritma TEA dan pontifex yang merupakan algortima kriptografi kunci rahasia, permasalahan tersebut dapat diatasi. Kekuatan algoritma ini terletak pada jaringan feistel (meliputi operasi subtitusi, permutasi dan modular arithmetic) dan bilangan delta yang berasal dari golden number.
\end{abstract}

Kata Kunci: Kriptografi, Dokumen, TEA, Pontifex.

\section{Abstract}

Data security is one of the most important aspects in information technology. With a high level of security, hopefully the information presented can be maintained its authenticity. In this final project a system that secures data and information stored on the computer from cryptanalysts is formed. The steps that the author did to make the process of forming the system include the stages of problem analysis, algorithm and flowchart along with modeling the structure of the program and design of the application interface, so that the application formed becomes easy to use and has optimal functions. By using TEA and pontifex algorithms which are secret key cryptographic algorithms, these problems can be overcome. The strength of this algorithm lies in the feistel network (including substitution operations, permutations and modular arithmetic) and delta numbers derived from the golden number.

Keywords: Cryptography, Documents, TEA, Pontifex.

\section{PENDAHULUAN}

Keamanan dokumen adalah hal yang sangat penting, apalagi dokumen yang dikirimkan adalah dokumen yang sangat rahasia. Berbagai usaha dilakukan untuk menjamin agar pesan rahasia yang dikirimkan tersebut tidak bisa diakses oleh pihak lain. Hal tersebut tentu saja akan menimbulkan resiko bilamana informasi yang sensitif dan berharga tersebut diakses oleh orangorang yang tidak berhak. Yang mana jika hal tersebut sampai terjadi, kemungkinan besar akan merugikan bahkan membahayakan orang yang mengirim pesan atau menerima pesan, maupun organisasinya. Informasi yang terkandung di dalamnya pun bisa saja berubah sehingga menyebabkan salah penafsiran oleh penerima pesan. Selain itu data yang dibajak tersebut akan memiliki kemungkinan rusak bahkan hilang.

Masalah yang sering terjadi dapat dilihat dari semakin meningkatnya tingkat kejahatan di internet, seperti hacking, cracking, carding, phising, spamming, dan defacing. Dengan latar belakang masalah inilah, maka dirancang bagaimana cara menjaga kerahasian dan mendeteksi keaslian dari informasi yang dikirim atau diterimanya. Hal tersebut tentu perlu dicegah agar kejadian-kejadian tindak pencurian data tidak berulang-ulang terjadi. Apabila semua data aman akan menjadikan individu ataupun institusi mendapat kepercayaan dari masyarakat sehingga menjamin keberlangsungan proses bisnis pada individu ataupun institusi tersebut. Untuk menghindari hal ini, maka dilakukan teknik pengamanan yang disebut kriptografi. Untuk pengamanan dokumen digunakan teknik kriptografi dengan menggunakan algoritma Tiny Encryption Algorithm (TEA). Kriptografi telah menjadi suatu bagian yang tidak dapat dipisahkan dari sistem keamanan jaringan. Ada berbagai algoritma kriptografi yang sekarang ini telah dan sedang dikembangkan, satu diantaranya algoritma kunci simetris ataupun asimetris (pembagian berdasarkan kunci). Salah satu metode enkripsi data adalah Tiny Encryption Algorithm (TEA).

Tiny Encryption Algorithm (TEA) merupakan suatu algoritma sandi yang diciptakan oleh David Wheeler dan Roger Needham (Computer Laboratory Cambridge University, England november 1994). Algoritma ini merupakan algoritma penyandian block cipher yang dirancang untuk penggunaan memori yang seminimal mungkin dengan kecepatan proses yang maksimal. Sistem penyandian TEA menggunakan proses feistel network dengan menambahkan fungsi matematik berupa penambahan dan pengurangan sebagai operator pembalik selain XOR. Hal ini dimaksudkan untuk menciptakan sifat nonlinearitas. Pergeseran dua arah (ke kiri dan ke kanan) menyebabkan semua bit kunci dan data bercampur secara berulang ulang [1].

\section{METODE PENELITIAN}

\subsection{Kriptografi}

Kriptografi (Cryptography) merupakan cabang ilmu pengetahuan yang menggunakan persamaan matematis untuk melakukan proses enkripsi maupun dekripsi data.Pada kriptografi modern proses enkripsi dan dekripsi biasanya dilakukan 
dengan kunci yang dipilih oleh pelaku komunikasi ataupun dapat dibangkitkan secara acak. Algoritma kriptografi modern seperti DES, AES, dan IDEA merupakan algoritma kriptografi modern yang sangat rumit dan kompleks. Algoritma kriptografi modern secara umum memiliki daya tahan yang cukup tinggi terhadap serangan, namun memiliki alur proses yang rumit serta membutuhkan sumber daya yang relative besar. Suatu pesan yang tidak disandikan disebut sebagai plaintext ataupun dapat disebut juga sebagai cleartext. Proses yang dilakukan untuk mengubah plaintext ke dalam ciphertext disebut encryption atau encipherment. Sedangkan proses untuk mengubah ciphertext kembali ke plaintext disebut decryption atau decipherment [2].

\subsection{Algoritma TEA}

Tiny Encryption Algorithm (TEA) merupakan suatu algoritma sandi yang diciptakan oleh David J. Wheeler dan Roger M. Needham dari Cambridge University tahun 1994. Algoritma ini merupakan algoritma penyandian block cipher yang dirancang untuk penggunaan memori yang seminimal mungkin dengan kecepatan proses yang maksimal. TEA memproses 64-bit input sekali waktu dan menghasilkan 64-bit output. TEA menyimpan 64-bit input kedalam L0 dan R0 masing masing 32-bit, sedangkan 128-bit kunci disimpan kedalam k[0], k[1], k[2], dan k[3] yang masing masing berisi 32-bit. Diharapkan teknik ini cukup dapat mencegah penggunaan teknik exshautive search secara efektif. Hasil output-nya akan disimpan dalam L16 dan R16. Bilangan delta konstan yang digunakan adalah 9E3779B9, dimana bilangan delta berasal dari golden number, digunakan delta $=(\sqrt{5}-1) 231$. Suatu bilangan delta ganda yang berbeda digunakan dalam setiap roundnya sehingga tidak ada bit dari perkalian yang tidak berubah secara teratur. Berbeda dengan struktur feistel yang semula hanya mengoperasikan satu sisi yaitu sisi sebelah kanan dengan sebuah fungsi F, pada algoritma TEA kedua sisi dioperasikan dengan sebuah fungsi yang sama [3].

Pada rumus enkripsi diketahui :

$L_{0}=L_{0}+f\left(R_{0}, k[0], k[1]\right.$, sum $)$

$R_{0}=R_{0}+f\left(L_{0}, k[2], k[3]\right.$, sum $)$

Sehingga untuk proses dekripsi digunakan rumus :

$L_{0}=L_{0}+f\left(R_{0}, k[1], k[0]\right.$, sum $)$

\subsection{Algoritma Pontifex}

Pontifex adalah jaringan permutasi substitusi 32-putaran (SPN) yang beroperasi pada empat kata 32-bit, sehingga memiliki ukuran blok 128 bit [3,11]. Pontifex mengenkripsi plaintext 128-bit ke 128-bit ciphertext dalam 32 putaran dengan 33 subkunci. Pengguna Panjang kunci diasumsikan variabel tetapi dalam proposal, itu tetap menjadi 128,192 atau 256 bit. Harus disebutkan bahwa kunci pendek dengan kurang dari 256 bit dipetakan ke kunci 256 bit dengan menambahkan satu '1' bit ke akhir MSB diikuti oleh sebanyak '0' bit yang diperlukan untuk menghasilkan 256 bit. Cipher terdiri dari IP permutasi awal, 32 putaran, dan FP permutasi final. Setiap putaran melibatkan operasi pencampuran kunci, melewati S-kotak, dan transformasi linear. Di babak terakhir, transformasi linear digantikan oleh operasi pencampuran tombol tambahan [4].

Langkah-langkah dalam melakukan enkripsi dan dekripsi dengan menggunakan algoritma pontifex antara lain :

1. Ambil sebuah karakter dari kata kunci

2. Lakukan enam langkah untuk mendapatkan huruf aliran kunci

3. Lakukan triple cut, sejumlah cut_size kartu awal diganti dengan kartu terakhir.

4. Lakukan pemindahan kartu berikutnya, dengan meletakan kartu pertama sebagai kartu paling bawah.

5. Dengan demikian proses untuk mendapatkan susunan kartu menurut karakter pertama dari kunci telah dilakukan. Langkah-langkah diatas diulangi untuk semua karakter lain dari kata kunci.

\section{HASIL DAN PEMBAHASAN}

Tahapan analisis terhadap suatu sistem dilakukan sebelum tahapan perancangan dilakukan. Adapun tujuan dilakukannya analisis terhadap suatu sistem adalah untuk mengetahui alasan mengapa sistem tersebut diperlukan, yaitu dengan merumuskan kebutuhan-kebutuhan dari sistem tersebut untuk meminimalisir sumber daya yang berlebih serta membantu merencanakan penjadwalan pembentukan sistem, meminimalkan distorasi-distorasi yang mungkin terdapat di dalam sistem tersebut sehingga dapat bekerja secara optimal. Untuk itu, analisa yang dilakukan terhadap perangkat lunak algoritma TEA ini akan dibagi kedalam beberapa aspek, yaitu analisa proses enkripsi dan deskripsi algoritma TEA.

1. Proses Enkripsi Algoritma TEA

Plainteks : YUDIKAQU

Kunci : TIKA S BUDIDARMA

Bagi plaintext menjadi 2 blok ke dalam blok R dan blok L:

$\mathrm{L}_{0}=$ YUDI

$\mathrm{R}_{0}=\mathrm{KAQU}$

Begitu juga dengan kunci, menjadi 4 blok k[0], k[1], k[2], k[3]:

$\mathrm{k}[0]=$ TIKA

$\mathrm{k}[1]=\operatorname{spcSspcB}$

$\mathrm{k}[2]=\mathrm{UDID}$ 
$\mathrm{k}[3]=\mathrm{ARMA}$

Ubah plaintext serta kunci dalam kode ASCII kemudian ke biner dengan proses sebagai berikut :

1. Plaintext (YUDIKAQU)

Sehingga di dapat :

Cipher $\mathrm{L}_{0}(\mathrm{z})=01011001010101010100010001001001$

Cipher $R_{0}(y)=01001011010000010101000101010101$

2. Kunci (TIKA S BUDIDARMA)

Sehingga di dapat :

$\mathrm{k}[0]=01010100010010010100101101000001$

$\mathrm{k}[1]=00100000 \quad 010100110010000001000010$

$\mathrm{k}[2]=01010101010001000100100101000100$

$\mathrm{k}[3]=01000001010100100100110101000001$

Cipher $\mathrm{R}_{0}(\mathrm{z})$ akan mengalami pergeseran bit ke kiri sebanyak 4 bit dan pergeseran ke kanan sebayak 5 bit.

Cipher $\mathrm{R}_{0}: 01001011010000010101000101010101$

Menjadi :

Zsl (Z shift left) $\quad$ : 10110100000101010001010101010100

Zsr (R shift right) : : 10101010010110100000101010001010

Zsl ditambahkan dengan kunci $\mathrm{k}[0]$ :

Zsl $\quad: 10110100000101010001010101010100$

$\mathrm{K}[0] \quad$ : 01010100010010010100101101000001

00001000010111100110000010010101

Sedangkan Zsr ditambahkan dengan kunci k[1] :

Zsr $\quad: 10101010010110100000101010001010$

$\mathrm{K}[1] \quad: 00100000010100110010000001000010$

11001010101011010010101011001100

Kemudian cipher $\mathrm{R}_{0}(\mathrm{Z})$ yang tidak mengalami pergeseran bit ditambahkan dengan bilangan delta, dimana bilangan delta yang digunakan secara konstanta yaitu : 9E3779B9 atau dalam biner 10011110001101110111100110111001

$\mathrm{R}(\mathrm{Z}): 01001011010000010101000101010101$

Delta : $10011110001101110111100110111001+$

11101001011110001100101100001110

Kemudian di xor kan dengan cipher Zsl yang ditambah K[0] :

11101001011110001100101100001110

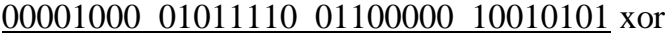

11100001001001101010101110011011

Kemudian di xor kan dengan cipher Zsr yang ditambah K[1] :

Untuk cipher $\mathrm{L}_{0}(\mathrm{Y})$ proses yang terjadi pada dasarnya sama seperti pada cipher $\mathrm{R}(\mathrm{z})$, yaitu cipher $\mathrm{L}(\mathrm{y})$ juga yang mengalami pergeseran bit ke kiri sebanyak 4 bit dan ke kanan sebanyak 5 bit.

Cipher $\mathrm{L}_{0}(\mathrm{y})$ : 01011001010101010100010001001001

Menjadi

Ysl : 10010101010101000100010010010101

Ysr : 01001010110010101010101000100010

Lsl ditambahkan dengan $\mathrm{k}[2]$ :

Ysl : 10010101010101000100010010010101

$\mathrm{K}[2]: \begin{array}{lllll}01010101 & 01000100 & 01001001 & 01000100+\end{array}$

11101010100110001000110111011001

Lsr ditambahkan dengan $\mathrm{k}[3]$ :

Ysr : 01001010110010101010101000100010

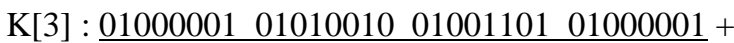

10001100000111001111011101100011

Cipher L (y) yang tidak mengalami pergeseran ditambah dengan delta

L(y) : 01011001010101010100010001001001

Delta : $10011110001101110111100110111001+$

11110111100011001011111000000010

Kemudian di xor kan dengan Ysl yang ditambah k[2]

Kemudian di xor kan dengan Ysr yang ditambah k[3]

Hasil akhir cipher $\mathrm{R}(\mathrm{Z})$ ditambahkan dengan chiper $\mathrm{L}(\mathrm{Y})$ yang tidak mengalami pergeseran, yang mana hasilnya akan dijadikan cipher L1(Y1) untuk round berikutnya. Demikian juga halnya hasil akhir pada cipher L(Y) akan ditambahkan dengan cipher $\mathrm{R}(\mathrm{Z})$ yang tidak mengalami pergeseran yang akan dijadikan cipher $\mathrm{R} 1(\mathrm{Z} 1)$ pada round berikutnya. 
$\mathrm{R}_{0}(\mathrm{Z}): 00101011100010111000000101010111$

$\mathrm{L}_{0}(\mathrm{Y}): \underline{01011001} 010101010100010001001001+$ $10000100111000001100010110100000=\mathrm{L}_{1}\left(\mathrm{Y}_{1}\right)$

$\mathrm{L}_{0}(\mathrm{Y}): 10010001000010001100010010111000$

$\mathrm{R}_{0}(\mathrm{Z}): 01001011010000010101000101010101+$ $11011100010010100001011000001101=R_{1}\left(Z_{1}\right)$

Round 1:

$\mathrm{Y}_{1}=\mathrm{y}+\left(((\mathrm{z}<<4)+\mathrm{k}[0])^{\wedge} \mathrm{z}+\operatorname{sum}^{\wedge}((\mathrm{z}>>5)+\mathrm{k}[1])\right)$

$\mathrm{Y}_{1}=100001001110000011000101 \quad 10100000+\left(\begin{array}{llll}10110100 & 00010101 & 00010101 & 01010100\end{array}\right)+\left(\begin{array}{lll}0 & 1010100 & 01001001\end{array}\right.$ $0100101101000001)^{\wedge} 11101001011110001100101100001110^{\wedge}(10101010010110100000101010001010)+$ (00100000 010100110010000001000010$)$

$\mathrm{Y}_{1}=10101110111010101100011111110111$

$Y_{1}=\begin{array}{llll}174 & 234 & 199 & 247\end{array}$

$\mathrm{Z}_{1}=\mathrm{Z}+\left(\left((\mathrm{y}<<4)+\mathrm{k}[2]^{\wedge} \mathrm{y}+\operatorname{sum}^{\wedge}((\mathrm{y}>>5)+\mathrm{k}[3])\right)\right.$

$\mathrm{Z}_{1}=11011100 \quad 01001010 \quad 0001011000001101+\left(\begin{array}{lllll}10010101 & 01010100 & 01000100 & 10010101\end{array}\right)+(0101010101000100$ $0100100101000100)^{\wedge} 11110111100011001011111000000010^{\wedge}(01001010110010101010101000100010)+$ (01000001 010100100100110101000001$)$

$\mathrm{Z}_{1}=10111101011100101110101010000111$

$\mathrm{Z}_{1}=\begin{array}{llll}189 & 114 & 234 & 135\end{array}$

Round 2:

$\mathrm{Y}_{2}=\mathrm{Y}_{1}+\left(((\mathrm{z}<<4)+\mathrm{k}[0])^{\wedge} \mathrm{Z}+\operatorname{sum}^{\wedge}((\mathrm{z}>>5)+\mathrm{k}[1])\right)$

$Y_{2}=10101110111010101100011111110111+(10110100000101010001010101010100)+(0101010001001001$ $0100101101000001)^{\wedge} 11101001011110001100101100001110^{\wedge}(10101010010110100000101010001010)$ $+(00100000010100110010000001000010)$

$Y_{2}=10010100100111001100100101001110$

$\mathrm{Y}_{2}=148 \quad 156 \quad 201 \quad 78$

$\mathrm{Z}_{2}=\mathrm{Z}_{1}+\left(\left((\mathrm{y}<<4)+\mathrm{k}[2]^{\wedge} \mathrm{y}+\operatorname{sum}^{\wedge}((\mathrm{y}>>5)+\mathrm{k}[3])\right)\right.$

$Z_{2}=10111101011100101110101010000111+\left(\begin{array}{llll}10010101 & 01010100 & 01000100 & 10010101\end{array}\right)+(0101010101000100$ $0100100101000100)^{\wedge} 11110111100011001011111000000010^{\wedge}(01001010110010101010101000100010)+$ (01000001 010100100100110101000001$)$

$\mathrm{Z}_{2}=11010011100110110011000100000001$

$Z_{2}=\begin{array}{llll}211 & 155 & 49 & 1\end{array}$

Perhitungan sampai round 32, akan diperoleh Ciphertext sebagai berikut :

Ciphertext= t á @ @

2. Proses Enkripsi Algoritma Pontifef

Plainteks : YUDIKAQU

Kunci : TIKABUDIDARMA

1. Penentuan nilai dari kartu keluaran untuk kunci $\mathbf{T}$

Nilai keluaran $=$ nilai kartu posisi $($ nilai kartu pertama +1$)$ dengan demikian posisi kartu keluaran adalah pada $(6+1)=7$ Maka kartu keluaran adalah pada posisi 7. Nilai kartu pada posisi 7 tersebut adalah 13. Kartu dengan nilai 13 adalah kartu king keriting. Sehingga hasilnya adalah :

Nilai keluaran : 13

Kartu keluaran : King keriting

2. Penentuan nilai dari kartu keluaran untuk kunci $\mathbf{I}$

Nilai keluaran $=$ nilai kartu pada posisi (nilai kartu pertama +1 ).dengan demikian posisi kartu keluaran adalah pada $(4+1)=5$.

Maka kartu keluaran adalah pada posisi 5. Nilai kartu pada posisi 5 tersebut adalah 9. Kartu dengan nilai 9 adalah Sembilan As. Sehingga hasilnya adalah

Nilai keluaran $=9$

Kartu keluaran $=$ Sembilan As

3. Penentuan nilai dari kartu keluaran untuk kunci $\underline{\mathbf{K}}$

Nilai keluaran $=$ nilai kartu pada posisi (nilai kartu pertama +1$)$ dengan demikian posisi kartu keluaran adalah pada $(5+1)=6$.

Maka kartu keluaran adalah pada posisi 6. Nilai kartu pada posisi 6 tersebut adalah 9. Kartu dengan nilai 9 adalah Sembilan As. Sehingga hasilnya adalah :

Nilai keluaran $=9$

Kartu keluaran $=$ Sembilan As.

3. Penentuan nilai dari keluaran untuk kunci $\underline{\mathbf{A}}$

Nilai keluaran $=$ nilai kartu pada posisi $($ nilai kartu pertama +1$)$.dengan demikian posisi kartu keluaran adalah pada (joker A atau $53+1)=54$ 
Maka kartu keluaran adalah pada posisi 54. Nilai kartu pada posisi 54 tersebut adalah joker B atau bernilai 54. Kartu dengan nilai 54 adalah pro As.karena melebihi 26, maka nilainya dikurangi 26 menjadi 28.Sehingga hasilnya adalah

Nilai keluaran $=28$

Kartu keluaran $=$ dua hati

4. Penentuan nilai dari kartu keluaran untuk kunci $\underline{\mathbf{B}}$

Nilai keluaran $=$ nilai kartu pada posisi (nilai kartu pertama +1 ) dengan demikian posisi kartu keluaran adalah pada $(4+1)=5$.

Maka kartu keluaran adalah pada posisi 5. Nilai kartu pada posisi 5 tersebut adalah 9. Kartu dengan nilai 9 adalah Sembilan As. Sehingga hasilnya adalah :

Nilai keluaran $=9$

Kartu keluaran $=$ Sembilan As.

5. Penentuan nilai dari kartu keluaran untuk kunci $\underline{\mathbf{U}}$

Nilai keluaran $=$ nilai kartu pada posisi (nilai kartu pertama +1$)$.dengan demikian posisi kartu keluaran adalah pada $(3+1)=4$.

Maka kartu keluaran adalah pada posisi 4. Nilai kartu pada posisi 4 tersebut adalah joker B atau sama dengan nilai 54. Kartu dengan nilai 54 adalah joker B. Sehingga hasilnya adalah

Nilai keluaran $=54$

Kartu keluaran $=$ joker B

6. Penentuan nilai dari kartu keluaran untuk kunci $\underline{\mathbf{D}}$

Nilai keluaran $=$ nilai kartu pada posisi (nilai kartu pertama +1$)$.dengan demikian posisi kartu keluaran adalah pada $(11+1)=12$.

Maka kartu keluaran adalah pada posisi 12. Nilai kartu pada posisi 12 tersebut adalah 23. Kartu dengan nilai 23 adalah Sepuluh Wajik. Sehingga hasilnya adalah

Nilai keluaran $=10$

Kartu keluaran $=$ Sepuluh wajik

7. Penentuan nilai dari kartu keluaran untuk kunci $\underline{\mathbf{I}}$

Nilai keluaran $=$ nilai kartu pada posisi (nilai kartu pertama +1 ).dengan demikian posisi kartu keluaran adalah pada $(4+1)=5$.

Maka kartu keluaran adalah pada posisi 5. Nilai kartu pada posisi 5 tersebut adalah 9. Kartu dengan nilai 9 adalah Sembilan As. Sehingga hasilnya adalah

Nilai keluaran $=9$

Kartu keluaran $=$ Sembilan As

8. Penentuan nilai dari kartu keluaran untuk kunci $\underline{\mathbf{D}}$

Nilai keluaran $=$ nilai kartu pada posisi (nilai kartu pertama +1 ).dengan demikian posisi kartu keluaran adalah pada $(52+1)=53$.

Maka kartu keluaran adalah pada posisi 53. Nilai kartu pada posisi 53 tersebut adalah 12. Kartu dengan nilai 12 adalah pro As. Sehingga hasilnya adalah

Nilai keluaran $=12$

Kartu keluaran $=$ pro As

9. Penentuan nilai dari kartu keluaran untuk kunci $\underline{\mathbf{A}}$

Nilai keluaran = nilai kartu pada posisi (nilai kartu pertama +1$)$.dengan demikian posisi kartu keluaran adalah pada (joker A atau $53+1)=54$.

Maka kartu keluaran adalah pada posisi 54. Nilai kartu pada posisi 54 tersebut adalah joker B atau bernilai 54. Kartu dengan nilai 54 adalah pro As.karena melebihi 26, maka nilainya dikurangi 26 menjadi 28.Sehingga hasilnya adalah

Nilai keluaran $=28$

Kartu keluaran $=$ dua hati

10. Penentuan nilai dari kartu keluaran untuk kunci $\underline{\mathbf{R}}$

Nilai keluaran $=$ nilai kartu pada posisi $($ nilai kartu pertama +1$)$.dengan demikian posisi kartu keluaran adalah pada $(12$ $+1)=13$.

Maka kartu keluaran adalah pada posisi 13. Nilai kartu pada posisi 13 tersebut adalah 37 . Kartu dengan nilai 37 adalah jack hati. .karena melebihi 26, maka nilainya dikurangi 26 menjadi 11. Sehingga hasilnya adalah

Nilai keluaran $=11$

Kartu keluaran $=$ jack As

11. Penentuan nilai dari kartu keluaran untuk kunci $\underline{\mathbf{M}}$

Nilai keluaran $=$ nilai kartu pada posisi (nilai kartu pertama +1$)$.dengan demikian posisi kartu keluaran adalah pada $(29$ $+1)=30$.

Maka kartu keluaran adalah pada posisi 30. Nilai kartu pada posisi 30 tersebut adalah 39. Kartu dengan nilai 39 adalah king hati. .karena melebihi 26, maka nilainya dikurangi 26 menjadi 13. Sehingga hasilnya adalah

Nilai keluaran $=13$

Kartu keluaran $=$ king As

12. Penentuan nilai dari kartu keluaran untuk kunci $\underline{\mathbf{A}}$ 
Nilai keluaran $=$ nilai kartu pada posisi $($ nilai kartu pertama +1$)$.dengan demikian posisi kartu keluaran adalah pada $(49$ $+1)=50$.

Maka kartu keluaran adalah pada posisi 50. Nilai kartu pada posisi 50 tersebut adalah 28. Kartu dengan nilai 28 adalah dua hati. karena melebihi 26, maka nilainya dikurangi 26 menjadi 2. Sehingga hasilnya adalah

Nilai keluaran $=2$

Kartu keluaran $=$ dua As

Setelah Sembilan kali pembangkitan keystream yang dilakukan di atas, maka keystream yang didapatkan adalah :

T I K A B U D I D A $\mathrm{R}$ M A

$\begin{array}{lllllllllllll}13 & 9 & 9 & 28 & 9 & 54 & 10 & 9 & 12 & 28 & 11 & 13 & 2\end{array}$

Dengan plainteks

Y U D I K A Q U

$\begin{array}{lllllllll}25 & 21 & 4 & 9 & 11 & 1 & 17 & 21\end{array}$

Maka penjumlahannya adalah

$\begin{array}{llllllllllllll}13 & 9 & 9 & 28 & 9 & 54 & 10 & 9 & 12 & 28 & 11 & 13 & 2\end{array}$

$\begin{array}{llllllll}25 & 21 & 4 & 9 & 11 & 1 & 17 & 21+(\bmod 26)\end{array}$

$\begin{array}{lllllllllllll}12 & 4 & 13 & 11 & 20 & 3 & 1 & 4 & 12 & 2 & 11 & 13 & 2\end{array}$

Maka cipherteks nya menjadi

$\begin{array}{lllllllllllll}12 & 4 & 13 & 11 & 20 & 3 & 1 & 4 & 12 & 2 & 11 & 13 & 2\end{array}$

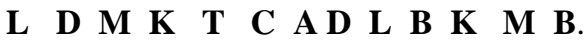

\section{KESIMPULAN}

Berdasarkan uraian pembahasan dari penelitian yang telah dilakukan, maka dapat diperoleh kesimpulan sebagai berikut:

1. Proses enkripsi dan dekripsi algoritma Tiny Encryption algorithm (TEA) memiliki panjang plainteks 64 bit dan panjang kunci 128 bit. Algoritma TEA memproses dengan 32 round sangat cocok digunakan untuk membangun sistem keamanan data yang mengandalkan kecepatan proses yang optimal.

2. Dalam proses enkripsi dan dekripsi meminimalkan memory dapat memaksimalkan proses, selain itu kapasitas file plaintext sama dengan kapasitas ciphertext sehingga dapat dijadikan otentikasi data.

\section{REFERENCES}

[1] M.A.Amri, dkk, 2009, "Pontifex Implementation In Quantum Cellular Automata", Journal IEEE Trans. On Computer, Vol. 58, No. 6, pp.721-727.

[2] Sony Bahagia Sinaga, 2018, "Pengamanan Pesan Komunikasi Menggunakan Algoritma Rsa, Rabbin Miller Dan Fungsi Sha-1 Serta Penanganan Man In The Middle Attack Dengan Interlock Protocol”, Jurnal Media Informasi Analisa dan Sistem (MEANS), Vol. 3, No.1.

[3] Ariyus, Dony, 2005, "Kriptografi Keamanan Data Dan Komunikasi”. Edisi Pertama. Yogyakarta. Graha Ilmu.

[4] Sadikin, Rifki, 2012, "Kriptografi Untuk Keamanan Jaringan”, Penerbit Andi, Yogyakarta.

[5] Ariyus, Dony, 2008, "Computer Security, Andi, Yogyakarta.

[6] Q. Mukti. 2014, "Kriptografi File Citra Menggunakan Algoritma TEA (Tiny Encryption Algorithm”, Jurnal Techsi, Vol. 5 No. 2 